\title{
Effect of diet on incipient colony success for two long-tongued bumblebee species in the laboratory
}

\author{
J. D. Carnell ${ }^{1}$ (1) $\cdot$ R. A. Hulse ${ }^{1} \cdot$ S. Page ${ }^{2} \cdot$ D. Goulson ${ }^{1} \cdot$ W. O. H. Hughes ${ }^{1}$
}

Received: 27 April 2020 / Revised: 7 October 2020 / Accepted: 26 October 2020 / Published online: 12 November 2020

(c) The Author(s) 2020

\begin{abstract}
Bumblebees (Bombus spp.) are ecologically and economically important pollinating insects and nutritional stress is one of the most significant factors causing their decline. However, our knowledge of the nutritional requirements of bumblebees is largely limited to just a small number of species that can be easily reared in the laboratory, so there is an important need to understand the nutritional requirements of a greater range of bumblebee species. In particular, the long-tongued, pocket maker species that have been intractable to laboratory rearing, yet are often of greatest conservation concern. Here, we compare the development and success of incipient colonies in two species of pocket maker bumblebees (B. pascuorum and $B$. hortorum) when fed either a less diverse or more diverse pollen diet. Our results show that both diets were sufficiently good for queens of both species to rear workers, but they performed significantly better for some variables on the less diverse diet. Our findings support previous work that suggests that a less diverse diet can be as good as a highly diverse mix in some respects. We also observed significant differences between species, demonstrating why we must not rely only on one or two model species to understand the effects of nutritional stress on bumblebee communities.
\end{abstract}

Keywords Pocket makers $\cdot$ Pollination $\cdot$ Bombus pascuorum $\cdot$ Bombus hortorum $\cdot$ Nutrition $\cdot$ Rearing

\section{Introduction}

Bumblebees (Bombus spp.) are ecologically and economically important pollinating insects for many wild flowering plants and crops (Garratt et al. 2014; Klein et al. 2007; Ollerton et al. 2011; Willmer 2011), but many species worldwide are experiencing significant declines due to multiple factors, including nutritional stress as a result of agricultural intensification and urbanisation (Carvell et al. 2006; Nieto et al. 2014; Ollerton et al. 2014; Williams and Osborne 2009). Bumblebees rely solely on the nutrients derived from pollen and nectar, with pollen providing proteins, polypeptides, free

Electronic supplementary material The online version of this article (https://doi.org/10.1007/s00040-020-00792-3) contains supplementary material, which is available to authorized users.

\section{J. D. Carnell}

j.carnell@ sussex.ac.uk

1 School of Life Sciences, University of Sussex, Falmer, Brighton, UK

2 Bumblebee Conservation Trust, Stirling University Innovation Park, Stirling, UK amino acids, lipids and sterols that are required for development, physiology and reproduction (Cardoza et al. 2012; Fliszkiewicz and Wilkaniec 2007; Genissel et al. 2002; Tasei and Aupinel 2008; Vanderplanck et al. 2014). The types, quantities, concentrations and ratios of these pollen constituents vary widely amongst plant groups (Cardoza et al. 2012; Roulston and Cane 2000). While most bumblebee species collect pollen from a variety of flower species to cover their nutritional needs (Kämper et al. 2016), many species exhibit morphological and behavioural biases towards particular plant groups (Goulson et al. 2005; Kleijn and Raemakers 2008; Roger et al. 2017). Increasing evidence suggests that adults, even without feedback from larvae, can identify highquality pollen and forage selectively on nutritionally rich floral resources to achieve a nutritional optimum (Dobson and Bergström 2000; Hanley et al. 2008; Ruedenauer et al. 2015).

A combination of selective foraging, interspecific pollen sourcing and pollen mixing (Somme et al. 2015) allows bees to reap benefits that a single pollen diet may not provide. For example, sunflower (Helianthus annus) pollen reduces worker longevity when consumed on its own, but when it is consumed in a polyfloral mix, it does not have this effect 
and in fact can be beneficial by reducing pathogen infection (Giacomini et al. 2018; LoCascio et al. 2019; McAulay and Forrest 2019) and diluting harmful toxic compounds (Eckhardt et al. 2014). Testing single and polyfloral pollen mixes demonstrate that diet can have extreme effects on bumblebee reproductive success (Baloglu and Gurel 2015; Moerman et al. 2015; Tasei and Aupinel 2008; Vanderplanck et al. 2014). While polyfloral mixes have been shown to improve reproductive performance (Tasei and Aupinel 2008), this is ultimately down to the specific pollens used. Moerman et al. (2017) demonstrated that diet suitability has less to do with interspecific plant diversity and more to do with the nutritional composition of the pollen meeting the specific resource requirements of the bee.

Nutritional requirements are likely to vary between species, reproductive state and energetic demands (Vaudo et al. 2015). However, investigations into the effect of nutrition on reproductive success of bumblebees have almost exclusively been carried out on a small number of generalist species such as B. terrestris (subgenus: Bombus) and B. impatiens (Pyrobombus), which are not generally suffering population declines or nutritional stress (Goulson et al. 2005), and which are confined to just 2 of the currently 38 recognised subgenera, both within the short-tongued, pollen storer clade (Cameron et al. 2007). These species are not representative of all bumblebees in their nutritional requirements. In a comparative assay using three pollens, workers of $B$. hypnorum and $B$. pratorum (Pyrobombus) not only performed worse than $B$. terrestris, regardless of pollen diet, but each species also responded differently to each pollen (Moerman et al. 2016). Non-B. terrestris/B. impatiens queens or incipient colonies are seldom studied, and yet nutrition plays a particularly important role during colony establishment; queen bumblebees must collect adequate quantities of pollen to meet not only their own physiological needs, but also that of their first brood as well. Proteins, sterols and lipids are required for ovary maturation (Aupinel et al. 2000; Tanaka et al. 2019; Vogt et al. 1998), and for brood development (Tasei and Aupinel 2008), while increased food intake in the early stages of development increases ongoing colony growth (Carvell et al. 2011; Herrmann et al. 2007; Westphal et al. 2009). It is perhaps not surprising that wild queens at this stage have also been recorded choosing high-quality pollen sources over low (Moquet et al. 2015), and this behaviour might be more common amongst more specialist species.

These results illustrate that while the bumblebees typically used as models in scientific investigation provide important insight into their physiology and behaviour, the results are not representative of all species or all bees within those species. To understand how diet affects bees both intra- and interspecifically, it is necessary to investigate different species and colonies at different developmental stages in experimental trials.
A large group of bumblebees that have been little investigated are the long-tongued species known as pocket makers. Unlike short-tongued, 'pollen storer' bumblebee species that feed their larvae a regurgitated liquid mix of nectar, pollen and glandular secretions, long-tongued bumblebees lay their eggs directly onto a pollen mass, which the larvae consume in its solid form (Den Boer and Duchateau 2006; Pereboom 2000). Long-tongued bumblebees are understudied because they are very difficult to rear in the laboratory, but recent developments now make rearing long-tonged bumblebees in the laboratory possible (Bučánková and Ptáček 2012; Carnell et al. 2020; Ptáček et al. 2015). Long-tongued bumblebee species are often more selective in their diet than short-tongued species, and many rely heavily on pollen from the Fabaceae plant group (Goulson 2003). Since both adult and larval feeding is somewhat different in these species to B. terrestris and B. impatiens, it is likely they will respond differently to pollen diets if they are less tolerant of toxic plant chemicals, or if their fundamental nutritional requirements differ.

Here, we investigate for the first time the nutritional requirements of long-tongued bumblebee incipient colonies, taking advantage of recent work enabling their laboratory rearing (Bučánková and Ptáček 2012; Carnell et al. 2020; Ptáček et al. 2015). We used B. pascuorum (Thoracobombus) and B. hortorum (Megabombus), both pocket maker species that are ecologically similar to many species of conservation concern, thus making them good models for investigating the biology of long-tongued bumblebees. We compare reproductive success and colony development of incipient colonies fed either a less diverse pollen diet or a more diverse pollen mix, with the aim of testing the success of these species on two commercially available and contrasting pollen mixes. We hypothesised that queens of both species should perform better on the more diverse mix, in which they can utilise the nutrients from a range of plant species.

\section{Materials and methods}

Sixty-two B. pascuorum queens and 20 B. hortorum queens were collected over a 13-day period between 25th March and 6th April 2018 from woodland and chalk downland sites in East Sussex (UK) (Supplementary Table 1). Site visits were only carried out on days with no rain or low cloud cover. Unequal sample sizes were due to $B$. hortorum being less common at these sites than B. pascuorum. Queens of both species were collected throughout the sampling period. Pollen collection occurs after queens have established a nest (Evans et al. 2007), and so only queens without pollen were collected. Queens were placed into individual, ventilated $15 \times 15 \times 15 \mathrm{~cm}$ plastic boxes in a dark room $\left(30{ }^{\circ} \mathrm{C}, 20 \%\right.$ rh). Each queen was housed separately and provided with 
$50 \%(\mathrm{v} / \mathrm{v})$ sugar water (10\% fructose, $90 \%$ sucrose) ad libitum. Queens were assigned randomly to one of two pollen diets: a less diverse pollen mix stated as being hawthorn (Crataegus monogyna) pollen, or a more diverse pollen mix stated as consisting of $75 \%$ pre-mixed wildflower, $15 \%$ heather (Erica sp.) and 10\% hawthorn pollens. All pollen was obtained from Pollenergie (France). Commercially available pollen such as these is collected by honey bees and may not necessarily contain pollen from plants favoured by bumblebee species that often forage on Fabaceae, which honey bees may only visit for nectar (Henning et al. 1992; Marzinzig et al. 2018). In addition, other studies have found pollen from plant species other than those stated in commercial mixes (Dance et al. 2017; Ruedenauer et al. 2020; Vanderplanck et al. 2018). We therefore refer to the hawthorn and wildflower pollen mixes as less diverse and more diverse, respectively, hypothesising that queens would perform poorly on the less diverse pollen mix, but that the more diverse mix might contain sufficient diversity to meet the nutritional needs of the bees. Pollen was ground to a powder and combined with 50\% (v/v) sugar water (10\% fructose, $90 \%$ sucrose) to form a sticky dough. Each queen was given a $1 \mathrm{~g}$ pollen ball every 2 days, which increased to $2 \mathrm{~g}$ when offspring were produced. To induce nesting behaviours, all queens were given a $3 \times 3 \mathrm{~cm}$ piece of cotton wool, which the queens readily used as nesting material. To encourage egg laying and brood rearing, queens were given a $B$. terrestris cocoon ( $>48 \mathrm{~h}$ old), from day 2 . The callow $B$. terrestris worker was removed as soon as it eclosed to avoid negative effects on the queen that can otherwise occur (Bučánková et al. 2012; Ptáček et al. 2015; Carnell et al. 2020). Cocoons were provided repeatedly until the queen had produced her own pupae.

It is generally accepted that stress caused by disturbance elicits defensive behaviours in bumblebees that are likely to inhibit oviposition and brood care (Bučánková and Ptáček 2012; Kirchner and Röschard 1999). Disturbance of the nest boxes was therefore kept to a minimum to reduce this and therefore we did not count the number of eggs or larvae produced during the experiment. To measure colony development, five variables that could be taken without interfering with the contents of the nest box were recorded every 2 days: whether or not queens produced (i) eggs, (ii) third stage (L3) larvae, and (iii) workers (binary data); and (iv) the number of weeks to the first L3 larvae, and (v) the number of workers produced by the end of the experiment (14 weeks).

The effects of bee species and diet on the colony variables were investigated in SPSS using generalised linear models. Model and link function were chosen based on data distributions and full models were chosen based on those with the lowest AIC values. Whether or not queens produced eggs, L3 larvae and workers was investigated using a binomial distribution and logit link function. The effects on the number of weeks to first L3 larvae and the number of workers produced at the end of 14 weeks were analysed using a Poisson distribution and $\log$ link function. Each analysis was run on the queens/colonies that reached that stage in colony development. Full factorial models with species, diet and their interaction were run for all analyses.

\section{Results}

Queens in both treatment groups fed on the pollen provided. All B. pascuorum and B. hortorum queens from both treatments that survived past Week $1(n=81)$ showed nesting behaviour by carding the cotton wool so that it either covered their nest box or formed part of their brood structures. The single queen that showed no nesting behaviour and died on Day 2 is excluded from further analysis. Over the 14 weeks of the study, 40 of the B. pascuorum queens (66\%) and 12 of the $B$. hortorum queens (60\%) laid eggs (Table 1 ). Across both species and treatments, all but one of the egglaying queens also successfully reared their brood to the L3 stage, which was reached between Weeks 2 and 12, and 21 of these (33\% B. pascuorum and 67\% B. hortorum) produced up to 5 workers (mean $\pm \mathrm{SE}=2.1 \pm 0.3$ workers per queen; Fig. 1). Offspring mortality ranged from $2 \%$ between egg and L3 stage, and $41 \%$ between L3 and worker. No dead pupae were observed. Following an infestation of wax moth, no further progress was expected, and the experiment was terminated at 14 weeks. The wax moths had proliferated and caused the destruction of comb structures, eggs and larvae, preventing a count of remaining offspring. No reproductives were produced during this period.

\section{The effect of diet and species on early-stage colony development}

There was a significant interaction between the effects of diet and bee species on the proportion of queens that produced eggs and L3 larvae, and the number of weeks before the first L3 larvae were produced (respectively, $\chi^{2}=4.02$, $d f=1, p=0.045 ; \chi^{2}=4.58, d f=1, p=0.032 ; \chi^{2}=4.44, d f=1$ $p=0.035$; Supplementary Table 1). Seventy-two percent of queens on the less diverse pollen laid eggs (14.5 \pm 6.5 eggs per queen), compared to $56 \%$ on the more diverse diet (11.5 \pm 7.5 ; Fig. 1), and only one queen which was fed the less diverse diet did not also produce L3 larvae $(14 \pm 6.5$ L3 larvae per queen). On average and across both treatments, $66 \%$ of B. pascuorum queens and $60 \%$ of $B$. hortorum queens laid eggs and for both species the first L3 larvae generally appeared in Week 6 (respectively after $6.05 \pm 0.41$ and $6.41 \pm 0.96$ weeks). Overall, queens reared on the more diverse mix produced L3 larvae a little earlier than those on the less diverse diet (respectively, $5.9 \pm 0.53 ; 6.4 \pm 0.54$ ); 
Table 1 Incipient colony success of wild-caught $B$ hortorum $(n=20)$ and $B$. pascuorum $(n=62)$ bumblebee queens in the laboratory over a 14-week period

\begin{tabular}{llll}
\hline Measure of queen success & Diet & B. pascuorum & B. hortorum \\
\hline Proportion of queens that produced eggs & Hawthorn & $68 \%(21 / 31)$ & $89 \%(8 / 9)$ \\
Proportion of queens that reared L3 larvae & Wildflower & $63 \%(19 / 30)$ & $36 \%(4 / 11)$ \\
& Hawthorn & $95 \%(20 / 21)$ & $100 \%(8 / 8)$ \\
Mean ( \pm SE) no. of weeks until L3 larvae were produced & Wildflower & $100 \%(19 / 19)$ & $100 \%(4 / 4)$ \\
& Hawthorn & $5.9 \pm 0.62$ & $7.5 \pm 1.05$ \\
Proportion of L3-producing queens that produced workers & Wildflower & $6.2 \pm 0.54$ & $4.25 \pm 1.60$ \\
& Hawthorn & $35 \%(7 / 20)$ & $50 \%(4 / 8)$ \\
Mean $( \pm$ SE) no. workers produced & Wildflower & $32 \%(6 / 19)$ & $100 \%(4 / 4)$ \\
& Hawthorn & $2.14 \pm 0.60$ & $2 \pm 0.41$ \\
& Wildflower & $1.83 \pm 0.65$ & $2.5 \pm 0.96$ \\
\hline
\end{tabular}

Bees were fed either a less diverse hawthorn diet or more diverse wildflower diet. Colony success was measured as whether queens (a) laid eggs, (b) reared third-stage (L3) larvae, (c) produced workers, and (d) the number of workers produced. Sample sizes for queens producing L3 larvae and workers are the total queens achieving the previous measure of success. No gynes or males were produced within the 14-week period however this effect varied between species, with B. pascuorum queens fed on the hawthorn diet producing L3 larvae earlier than those fed on the wildflower diet and the opposite being the case for $B$. hortorum (Table 1 ).

\section{The effect of diet and species on late-stage colony development}

Based on the queens which produced L3 larvae $(n=51)$, there was a significant interaction between diet and species on the proportion of queens that produced workers $\left(\chi^{2}=3.87, d f=1, p=0.049\right)$. Thirty-three percent of $B$. pascuorum queens produced workers $(6 \pm 6.5$ workers per queen), compared to $67 \%$ of $B$. hortorum queens (all of which produced 4 workers per queen). There were no significant effects of species or diet on the number of workers produced (respectively, $\chi^{2}=0.15, d f=1, p=0.70, \chi^{2}=0.012$, $d f=1, p=0.91$; Supplementary Table 1).

\section{Discussion}

We found that queens of $B$. pascuorum and B. hortorum can survive and successfully rear workers on both the less diverse hawthorn pollen and the more diverse wildflower mix and that a less diverse pollen mix can be as good as a more diverse one. A wax moth infestation developed towards the end of the experiment, but despite this, and the additional stress it may have imposed on queens, the proportion of queens that laid eggs was amongst the highest observed in these species when reared in captivity (Bučánková et al. 2012; Ptáček et al. 2015; Carnell et al. 2020). Very few workers are required for queens to switch to male production (Carnell et al. 2020), so it is quite likely that in the absence of wax moths this would have occurred.
Perhaps surprisingly, we found that a less diverse diet could be as good as, if not better than, a more diverse diet in some respects. B. pascuorum queens fed the less diverse (hawthorn) pollen were just as likely to lay eggs as those on the more diverse mix, and $B$. hortorum queens were indeed more likely to lay eggs when fed the less diverse pollen. Hawthorn is not a natural foraging choice for queens of these species; in the UK its open-bowl flowers appear in May and are usually pollinated by flies and small bees (Corbet 2006; García and Chacoff 2007), whereas B. pascuorum and B. hortorum start emerging in March (Falk 2015) and favour plants with flowers a little deeper than their tongue length ( 10-13 mm) (Barrow and Pickard 1984; Brian 1957; PrŷsJones and Corbet 1991). Despite this and across all treatments, offspring mortality between egg and L3 stage was very low, demonstrating both the less diverse hawthorn mix and the more diverse wildflower pollen mix were adequate for early-stage larval development. Interestingly, for queens in both treatments, much higher mortality was observed in offspring between the L3 and worker stage, which could be pinpointed to the L3 and L4 stages because we observed no dead pupae. This suggests that in the critical period just before pupation (Plowright and Jay 1977), larvae may be more sensitive to quantitative and/or qualitative deficiencies in pollen or other stresses. This was especially obvious in $B$. pascuorum and could indicate differences between the species in their nutritional biology or tolerance to the conditions of captive rearing. Some may have died of starvation if the queen failed to replenish the pollen pockets and the effect of this on the larvae may only be visible when they have the highest resource demands (Plowright and Jay 1977). We did not find any evidence that the pollen delayed larval growth, as has previously been reported (Genissel et al. 2002). However, we intentionally avoided any methods of data collection that might have increased queen stress and 
a

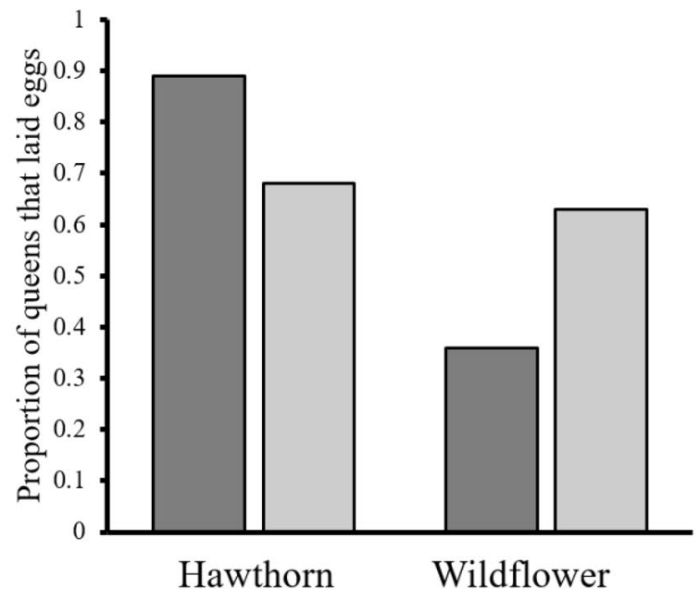

b

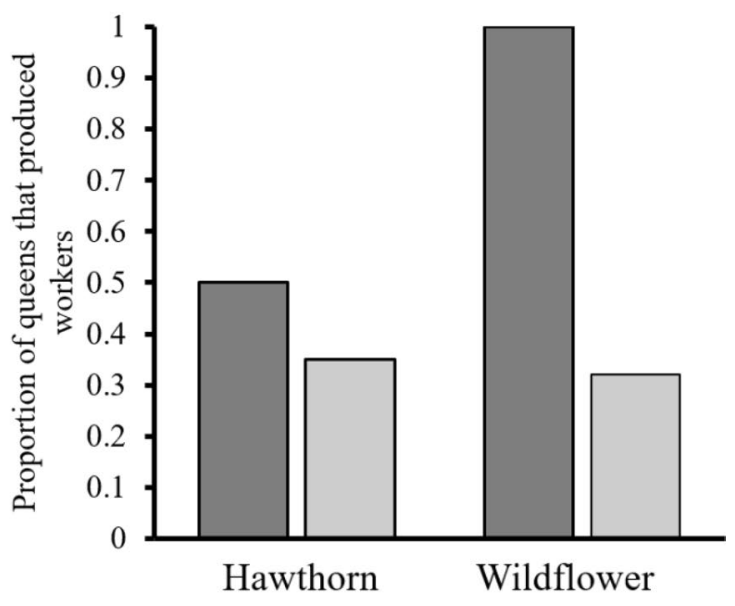

B. hortorum $\square$ B. pascuorum

c

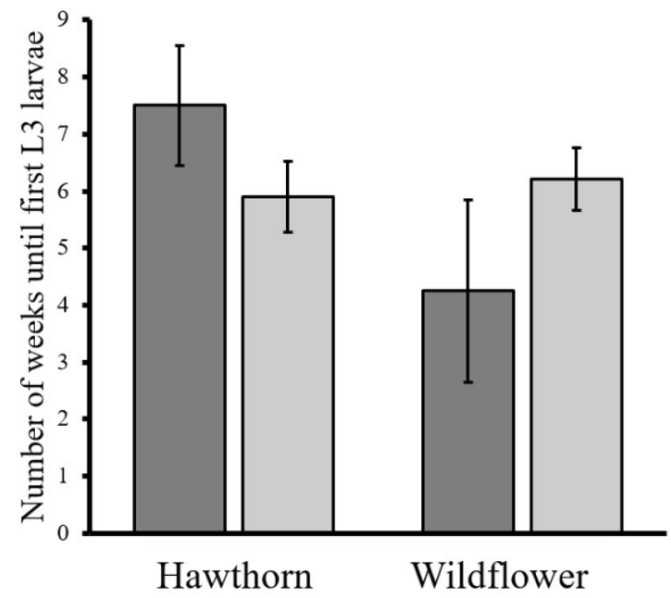

Fig. 1 Effect of diet on incipient colony success of wild-caught $B$. hortorum ( $n=20$; dark grey) and B. pascuorum ( $n=61$; light grey) bumblebee queens in the laboratory measured by a proportion of queens that laid eggs in captivity $(n=52)$, $\mathbf{b}$ proportion of queens that reared third-stage larvae (L3) to workers $(n=21)$, c mean $( \pm \mathrm{SE})$ number of weeks before the first L3 larvae were produced, and d

interfered with colony production. More intricate measures of long-tongued bumblebee species will be possible with practice and when increasingly intensive experiments can be carried out. The failure of queens to feed their larvae is a significant hindrance to pocket maker rearing, and future work should attempt to elucidate precisely when queens are most sensitive to external conditions, and how this could be mitigated to encourage egg laying and ongoing brood care.

Egg-laying success was more affected by diet for $B$. hortorum queens, with twice as many laying eggs when they were fed on the less diverse diet compared to the more d

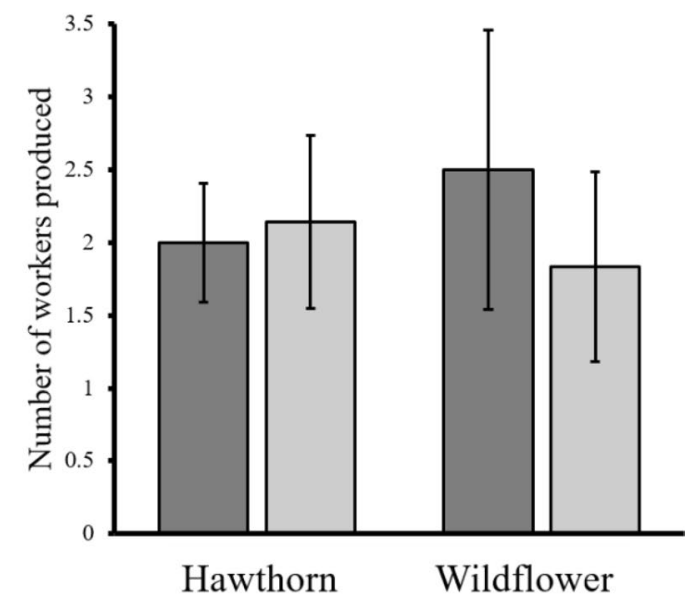

mean $( \pm \mathrm{se})$ number of workers produced. Queens were randomly assigned a diet treatment of either less diverse hawthorn pollen or a more diverse wildflower pollen mix. Only one egg-laying queen (a $B$. pascuorum on the hawthorn diet) did not produce L3 larvae (Supplementary Fig. 1)

diverse diet. Almost all queens that produced eggs produced L3 larvae, but there was a significant difference between species in success from L3 to the adult worker stage, with a significantly greater proportion of the $B$. hortorum queens successfully rearing workers. That no dead pupae were observed suggests a species difference arose at the L3/L4 stage which may be a critical period of sensitivity to nutritional stress (Sutcliffe and Plowright 1990). Qualitative differences in macronutrients (e.g. protein content) between diets could explain the variation in worker production if the pollens were nutritionally more suitable for the $B$. hortorum larvae, 
or if they contained compounds harmful to B. pascuorum. Regardless of the mechanism, the results suggest fundamental differences in the nutritional requirements of these bees. Differences in the life history traits of bumblebees is likely to explain some variation in the nutritional biology observed between these and other bumblebee species (Moerman et al. 2016; Persson et al. 2015; Vaudo et al. 2015), highlighting how essential it is to consider the needs of individual species to fully understand how wild bee communities are affected by nutritional stress. B. pascuorum and B. hortorum are ecologically similar, both being temperate, annual, longtongued species. While it is possible that the differences we observed arose from factors such as queen health and infection status, it may be that even subtle differences in physiology are reflected in their nutritional demands. For example, B. pascuorum has a smaller foraging range (Wood et al. 2015), but a longer colony life cycle than $B$. hortorum (Benton 2006), which may affect the capacity of both queen and workers to tolerate periods of nutritional stress. Because both of these species are pocket makers and we are still in the early days of rearing optimisation, it is important not to discount the effects of queen behaviour on colony success. In personal observations of the queens here and in our previous work, we found $B$. hortorum queens to be much more sensitive to physical disturbances (Carnell et al. 2020). Although this does not explain our findings here, decades of rearing work on a variety of species has clearly demonstrated that bumblebee species vary widely in their performance under captive conditions, across and within the pocket maker and pollen storer groups (Fandiño 2007; Ptáček et al. 2015; Sheikh 2016; Velthuis and Van Doorn 2006). It is possible that in spite of being more sensitive to disturbance, $B$. hortorum is behaviourally more suited to captive rearing. Individual difference amongst bumblebees may have also had an effect, e.g. quality of larval diet, number of days post-emergence on which they were captured and infection status. We did not screen for pathogens here, which may have affected queen performance. Work on other bumblebee species show such factors can have a pronounced effect on queen founding success and colony development, so further work is needed to determine how the developmental conditions affect $B$. pascuorum and $B$. hortorum queens in this way (Rutrecht and Brown 2008; Woodard et al. 2019).

Irrespective of the possible physiological and behavioural differences between these species, the fact that the number of workers was not different between $B$. pascuorum and $B$. hortorum suggests that both diets were sufficient for worker production. Adequate larval feeding is essential for bumblebee survival, so clearly the larvae were provisioned with enough food to survive and mature into workers (Plath 1934; Wilson 1971). These workers were small, but this also occurs in wild colonies (Alford 1975). The production of workers depends on investment in larval feeding by the queen and diet quality; it seems both were adequate in this case, but with room for improvement. Future studies could try placing these young colonies into the field, so new workers can self-select food for the colony and provision their larvae under more natural conditions.

In previous experimental trials using donor cocoons for long-tongued bee rearing, avoidance and aggression have often been observed between queens and the emerging donor workers, sometimes leading to a cessation of queen reproduction (Bučánková et al. 2012; Ptáček et al. 2015; Carnell et al. 2020). We removed donor callows as soon as they emerged and relied only on the cocoons themselves to encourage egg laying and brood care. Queens should identify these as foreign (Gamboa et al. 1987; Heinrich 1974) and perceive a rival queen is present (Goulson et al. 2018; Lopez-Vaamonde et al. 2004). This should encourage her to out-compete it by producing her own colony. We found that repeated cocoon exposure was indeed an effective method to trigger oviposition, which is particularly useful for bumblebee species unsuited to interspecific cohabitation. Pocket makers feed their larvae pollen primarily through mass provisioning, but the pollen masses are known to be refilled over time and it seems to be this specific behaviour that queens fails to perform in captivity (Bučánková and Ptáček 2012).

Nutrition clearly plays an important role in queen reproductive success during colony establishment and our results support previous work suggesting that a less diverse diet can be as good as, if not better than, a more diverse diet (Moerman et al. 2017). Our results show that the diets tested are adequate for rearing B. pascuorum and B. hortorum, although it is likely the colonies would have performed much better on diets containing their natural forage plants (e.g. a Fabaceae pollen). Our results also suggest that different bumblebee species may have different nutritional requirements, demonstrating the value of studying a range of bumblebee species to fully understand the effects of biological stressors such as nutritional stress. Despite a serious wax moth infestation towards the end of the experiment, our queens achieved amongst the highest success rate of oviposition recorded in long-tongued bumblebees reared in the laboratory. Challenges remain, including the need for more detailed measurements of the effects of diet in pocket maker species that do not disrupt colony progress. Future work should focus on comparing long-tongued species with reliable models such as $B$. terrestris. The results here and those drawn from Carnell et al. (2020) suggest species respond differently to captivity and it is important that future studies attempt to test the effects of capture, transit, diet and the conditions of captive nesting separately on different species. Honey bee colonies that are transported over long distances for pollination exhibit higher stress levels than stationary ones (Simone-Finstrom et al. 2016), and it is possible that 
chronic effects of capture, transport and handling may affect queens, but this effect may vary between species. The results here show that survival of queens following capture can be relatively high and so it is important that future studies maximise sample size through intensive queen collection. Although biochemical analysis of the pollen diets was not conducted, characterisation of the protein, lipid and amino acid content may elucidate the differential responses we observed. There is a great deal to be gained from studying the effects of nutritional stress on a variety of bumblebee species. Achieving this is key to developing evidence-based conservation management to protect diverse bumblebee communities.

\section{Availability of data and material}

Data are available in supplementary material.

Acknowledgements We thank NERC (NE/M009491/1) and the Bumblebee Conservation Trust for funding, and Maria Clara Castellanos, Richard Gill, Sara Leonhardt and an anonymous reviewer for comments on the manuscript.

Author contributions JDC, SP, DG and WOHH conceived the research; WOHH and JDC designed the experiment; JDC and RAH collected bees, JDC carried out the experiment; JDC and WOHH performed analyses; JDC wrote the paper.

Funding NERC (NE/M009491/1) and the Bumblebee Conservation Trust (BBCT).

\section{Compliance with ethical standards}

Conflict of interest The authors declare that they have no conflict of interest.

Open Access This article is licensed under a Creative Commons Attribution 4.0 International License, which permits use, sharing, adaptation, distribution and reproduction in any medium or format, as long as you give appropriate credit to the original author(s) and the source, provide a link to the Creative Commons licence, and indicate if changes were made. The images or other third party material in this article are included in the article's Creative Commons licence, unless indicated otherwise in a credit line to the material. If material is not included in the article's Creative Commons licence and your intended use is not permitted by statutory regulation or exceeds the permitted use, you will need to obtain permission directly from the copyright holder. To view a copy of this licence, visit http://creativecommons.org/licenses/by/4.0/.

\section{References}

Alford DV (1975) Bumblebees. Davis-Poynter, London

Aupinel P, Genissel A, Tasei J-N, Poncet J, Gomond S (2000) Collection of spring pollens by Bombus terrestris queens. Assessment of attractiveness and nutritive value of pollen diets. In: VIII International Symposium on Pollination-Pollination: Integrator of Crops and Native Plant Systems 561, pp 101-105

Baloglu GH, Gurel F (2015) The effects of pollen protein content on colony development of the bumblebee, Bombus terrestris L. J Apic Sci 59:83-88

Barrow D, Pickard R (1984) Size-related selection of food plants by bumblebees. Ecol Entomol 9:369-373

Benton T (2006) Bumblebees: the natural history and identification of the species found in Britain, vol 98. Harper, UK

Brian AD (1957) Differences in the flowers visited by four species of bumble-bees and their causes. J Anim Ecol 26:71-98

Bučánková A, Ptáček V (2012) A test of Bombus terrestris cocoon and other common methods for nest initiation in B. lapidarius and $B$. hortorum. J Apic Sci 56:37-47

Cameron SA, Hines H, Williams P (2007) A comprehensive phylogeny of the bumble bees (Bombus). Biol J Linn Soc 91:161-188

Cardoza YJ, Harris GK, Grozinger CM (2012) Effects of soil quality enhancement on pollinator-plant interactions. Psyche 2012:8. https://doi.org/10.1155/2012/581458

Carnell JD, Page S, Goulson D, Hughes WOH (2020) Trialling techniques for rearing long-tongued bumblebees under laboratory conditions. Apidologie 51:254-266

Carvell C, Roy DB, Smart SM, Pywell RF, Preston CD, Goulson D (2006) Declines in forage availability for bumblebees at a national scale. Biol Conserv 132:481-489

Carvell C, Osborne JL, Bourke AFG, Freeman SN, Pywell RF, Heard MS (2011) Bumble bee species' responses to a targeted conservation measure depend on landscape context and habitat quality. Ecol Appl 21:1760-1771. https://doi.org/10.1890/10-0677.1

Corbet SA (2006) A typology of pollination systems: implications for crop management and the conservation of wild plants. Plant-pollinator interactions: from specialization to generalization. University of Chicago Press, Chicago, pp 315-340

Dance C, Botías C, Goulson D (2017) The combined effects of a monotonous diet and exposure to thiamethoxam on the performance of bumblebee micro-colonies. Ecotox Environ Safe 139:194-201

Den Boer SPA, Duchateau M (2006) A larval hunger signal in the bumblebee Bombus terrestris. Insectes Soc 53:369-373

Dobson HEM, Bergström G (2000) The ecology and evolution of pollen odors. Plant Syst Evol 222:63-87

Eckhardt M, Haider M, Dorn S, Müller A (2014) Pollen mixing in pollen generalist solitary bees: a possible strategy to complement or mitigate unfavourable pollen properties? J Anim Ecol 83:588-597

Evans E, Burns I, Spivak M (2007) Befriending bumble bees: a practical guide to raising local bumble bees. University of Minnesota Extension Service, St. Paul

Falk SJ (2015) Field guide to the bees of Great Britain and Ireland. British Wildlife Publishing, Faringdon

Fandiño MTA (2007) Management of Bombus atratus bumblebees to pollinate lulo (Solanum quitoense $\mathrm{L}$ ), a native fruit from the Andes of Colombia, vol 50. Cuvillier Verlag, Göttingen

Fliszkiewicz M, Za W (2007) Fatty acids and amino acids in the fat body of bumblebee Bombus terrestris (L.) in diapausing and nondiapausing queens. J Apic Sci 51:55-63

Gamboa GJ, Foster RL, Richards KW (1987) Intraspecific nest and brood recognition by queens of the bumble bee, Bombus occidentalis (Hymenoptera: Apidae). Can J Zool 65:2893-2897

García D, Chacoff NP (2007) Scale-dependent effects of habitat fragmentation on hawthorn pollination, frugivory, and seed predation. Conserv Biol 21:400-411

Garratt MP et al (2014) The identity of crop pollinators helps target conservation for improved ecosystem services. Biol Conserv 169:128-135 
Genissel A, Aupinel P, Bressac C, Tasei JN, Chevrier C (2002) Influence of pollen origin on performance of Bombus terrestris microcolonies. Entomol Exp Appl 104:329-336

Giacomini JJ, Leslie J, Tarpy DR, Palmer-Young EC, Irwin RE, Adler LS (2018) Medicinal value of sunflower pollen against bee pathogens. Sci Rep 8:14394

Goulson D (2003) Bumblebees. Behaviour and ecology. Oxford University Press, Oxford

Goulson D, Hanley ME, Darvill B, Ellis J, Knight ME (2005) Causes of rarity in bumblebees. Biol Conserv 122:1-8

Goulson D, O'Connor S, Park KJ (2018) Causes of colony mortality in bumblebees. Anim 21:45-53

Hanley ME, Franco M, Pichon S, Darvill B, Goulson D (2008) Breeding system, pollinator choice, and variation in pollen quality in British herbaceous plants. Funct Ecol 22:592-598

Heinrich B (1974) Pheromone induced brooding behavior in Bombus vosnesenskii and B. edwardsii (Hymenoptera: Bombidae). J Kans Entomol Soc 47:396-404

Henning JA, Peng Y-S, Montague MA, Teuber LR (1992) Honey bee (Hymenoptera: Apidae) behavioral response to primary alfalfa (Rosales: Fabaceae) floral volatiles. J Econ Entomol $85: 233-239$

Herrmann F, Westphal C, Moritz RF, Steffan-Dewenter I (2007) Genetic diversity and mass resources promote colony size and forager densities of a social bee (Bombus pascuorum) in agricultural landscapes. Mol Ecol 16:1167-1178. https://doi.org/10.1111/ j.1365-294X.2007.03226.x

Kämper W, Werner PK, Hilpert A, Westphal C, Blüthgen N, Eltz T, Leonhardt SD (2016) How landscape, pollen intake and pollen quality affect colony growth in Bombus terrestris. Landsc Ecol 31:2245-2258

Kirchner W, Röschard J (1999) Hissing in bumblebees: an interspecific defence signal. Insectes Soc 46:239-243

Kleijn D, Raemakers I (2008) A retrospective analysis of pollen host plant use by stable and declining bumble bee species. Ecology 89:1811-1823

Klein AM, Vaissiere BE, Cane JH, Steffan-Dewenter I, Cunningham SA, Kremen C, Tscharntke T (2007) Importance of pollinators in changing landscapes for world crops. Proc Royal Soc B 274:303-313

LoCascio GM, Aguirre L, Irwin RE, Adler LS (2019) Pollen from multiple sunflower cultivars and species reduces a common bumblebee gut pathogen. R Soc Open Sci 6:190279

Lopez-Vaamonde C, Koning JW, Brown RM, Jordan WC, Bourke AF (2004) Social parasitism by male-producing reproductive workers in a eusocial insect. Nature 430:557

Marzinzig B, Brünjes L, Biagioni S, Behling H, Link W, Westphal C (2018) Bee pollinators of faba bean (Vicia faba L.) differ in their foraging behaviour and pollination efficiency. Agric, Ecosyst Environ 264:24-33

McAulay M, Forrest J (2019) How do sunflower pollen mixtures affect survival of queenless microcolonies of bumblebees (Bombus impatiens)? Arthropod-Plant Inte 13:517-529

Moerman R et al (2015) Growth rate of bumblebee larvae is related to pollen amino acids. J Econ Entomol. https://doi.org/10.1093/ jee/tov279

Moerman R, Roger N, De Jonghe R, Michez D, Vanderplanck M (2016) Interspecific variation in bumblebee performance on pollen diet: new insights for mitigation strategies. PLoS ONE 11:e0168462

Moerman R, Vanderplanck M, Fournier D, Jacquemart AL, Michez D (2017) Pollen nutrients better explain bumblebee colony development than pollen diversity. Insect Conserv Diver 10:171-179

Moquet L, Mayer C, Michez D, Wathelet B, Jacquemart A-L (2015) Early spring floral foraging resources for pollinators in wet heathlands in Belgium. J Insect Physiol 19:837-848. https://doi. org/10.1007/s10841-015-9802-5
Nieto A et al (2014) European red list of bees. Publication Office of the European Union, Luxembourg

Ollerton J, Winfree R, Tarrant S (2011) How many flowering plants are pollinated by animals? Oikos 120:321-326. https://doi.org/1 0.1111/j.1600-0706.2010.18644.x

Ollerton J, Erenler H, Edwards M, Crockett R (2014) Extinctions of aculeate pollinators in Britain and the role of large-scale agricultural changes. Science 346:1360-1362. https://doi.org/10.1126/ science. 1257259

Pereboom J (2000) The composition of larval food and the significance of exocrine secretions in the bumblebee Bombus terrestris. Insectes Soc 47:11-20

Persson AS, Rundlöf M, Clough Y, Smith HG (2015) Bumble bees show trait-dependent vulnerability to landscape simplification. Biol Conserv 24:3469-3489. https://doi.org/10.1007/s1053 1-015-1008-3

Plath OE (1934) Bumblebees and their ways. Bumblebees and their ways

Plowright R, Jay S (1977) On the size determination of bumble bee castes (Hymenoptera: Apidae). Can J Zool 55:1133-1138

Prŷs-Jones PE, Corbet SA (1991) Bumblebees. Richmond Publishing, Slough

Ptáček V, Votavová A, Komzáková O (2015) Experience in rearing common carder bees (Bombus pascuorum Scop.), with some notes on three similar species: shrill carder bee (B. sylvarum L.), red-shanked carder bee (B. ruderarius Müll.), and brown-banded carder bee (B. humilis Ill.)(Hymenoptera: Apidae). Acta Univ Agric Silvic Mendel Brun 63:1535-1542

Roger N et al (2017) Impact of pollen resources drift on common bumblebees in NW Europe. Glob Change Biol 23:68-76

Roulston TH, Cane JH (2000) Pollen nutritional content and digestibility for animals. Plant Syst Evol 222:187-209

Ruedenauer FA, Spaethe J, Leonhardt SD (2015) How to know which food is good for you: bumblebees use taste to discriminate between different concentrations of food differing in nutrient content. J Exp Biol 218:2233-2240

Ruedenauer FA, Sydow D, Spaethe J, Leonhardt SD (2020) Young bumblebees may rely on both direct pollen cues and early experience when foraging. Proc R Soc B 287:20201615

Rutrecht ST, Brown MJ (2008) The life-history impact and implications of multiple parasites for bumble bee queens. Int J Parasitol 38:799-808

Sheikh UAA (2016) Eco-biological studies on bumblebee (Bombus haemorrhoidalis Smith) from Northern Pakistan in relation to crop pollination. Higher Education Commission, Pakistan

Simone-Finstrom M, Li-Byarlay H, Huang MH, Strand MK, Rueppell O, Tarpy DR (2016) Migratory management and environmental conditions affect lifespan and oxidative stress in honey bees. Sci Rep 6:32023

Somme L et al (2015) Pollen and nectar quality drive the major and minor floral choices of bumble bees. Apidologie 46:92-106. https ://doi.org/10.1007/s13592-014-0307-0

Sutcliffe G, Plowright R (1990) The effects of pollen availability on development time in the bumble bee Bombus terricola K. (Hymenoptera: Apidae). Can J Zool 68:1120-1123

Tanaka CS, Ikemoto M, Nikkeshi A, Kanbe Y, Mitsuhata M, Yokoi T (2019) Ovarian development related to pollen feeding in workers of the bumblebee Bombus ignitus (Hymenoptera: Apidae). Appl Enotomol Zool 54:85-89

Tasei J-N, Aupinel P (2008) Nutritive value of 15 single pollens and pollen mixes tested on larvae produced by bumblebee workers (Bombus terrestris, Hymenoptera: Apidae). Apidologie 39:397-409

Vanderplanck M, Moerman R, Rasmont P, Lognay G, Wathelet B, Wattiez R, Michez D (2014) How does pollen chemistry impact 
development and feeding behaviour of polylectic bees? PLoS ONE 9:e86209

Vanderplanck M et al (2018) Is non-host pollen suitable for generalist bumblebees? Insect Sci 25:259-272

Vaudo AD, Tooker JF, Grozinger CM, Patch HM (2015) Bee nutrition and floral resource restoration. Curr Opin Insect Sci 10:133-141

Velthuis HH, Van Doorn A (2006) A century of advances in bumblebee domestication and the economic and environmental aspects of its commercialization for pollination. Apidologie 37:421-451

Vogt FD, Heinrich B, Plowright C (1998) Ovary development in bumble bee queens: the influence of abdominal temperature and food availability. Can J Zool 76:2026-2030

Westphal C, Steffan-Dewenter I, Tscharntke T (2009) Mass flowering oilseed rape improves early colony growth but not sexual reproduction of bumblebees. J Appl Ecol 46:187-193
Williams PH, Osborne JL (2009) Bumblebee vulnerability and conservation world-wide. Apidologie 40:367-387

Willmer P (2011) Pollination and floral ecology. Princeton University Press, Princeton

Wilson EO (1971) The insect societies, vol 311. Belknap Press of Harvard University, Cambridge

Wood TJ, Holland JM, Hughes WO, Goulson D (2015) Targeted agrienvironment schemes significantly improve the population size of common farmland bumblebee species. Mol Ecol 24:1668-1680

Woodard SH, Duennes MA, Watrous KM, Jha S (2019) Diet and nutritional status during early adult life have immediate and persistent effects on queen bumble bees. Conserv Physiol 7:coz048 